land, already heavily exploited, might well be more difficult.

\section{Physical Research in Africa}

Dr. B. N. C. Agu of the Department of Physics, the University of Ibadan, Nigeria, writes in retrospect of the problems discussed at the eighth annual conference of the Science Association of Nigeria earlier this year:

Most indigenous scientists, including those who graduate at home, tend to do their postgraduate research abroad for two main reasons. One is because of the limited facilities in most parts of Africa for research in the branches of physical sciences in which the students wish to work, including nuclear physics, electronics, metallurgy, solid-state physics, health physies and radio-astronomy. Another group of postgraduate students goes abroad in search of a doctorate from a reputable university in the United Kingdom or North America. Many of these will eventually return to take up teaching assignments in the local universities.

Most of the scientists who take postgraduate degrees abroad soon find in Africa that the convenient set-up on which they worked in the older universities abroad is no longer available to them. Should they attempt to maintain a tenuous umbilical cord with their mother universities abroad in order to continue research, or try to make a fresh start in African universities?

This latter procedure requires years before any progress is made and large sums of money which are not usually readily available. The purchase, replacement and repair of research equipment can be very frustrating. Orders for equipment take several months to arrive and the replacement of defunct parts takes even longer. The problem of getting and retaining competent technicians is almost insurmountable. Without enough local experience the repair and maintenance of research equipment become a major operation which can hold up important work for months.

In recent years, several countries and international organizations have been showing interest in developing research in Africa. However, a quick survey of the fields in which research is supported by these bodies shows a bias towards agriculture and veterinary science, African studies, population problems, child health, medicine and malnutrition problems in the developing countries. For the five year period 19611965 the distribution of foreign benefactions to the various departments of the University of Ibadan and its Teaching Hospital was as follows:

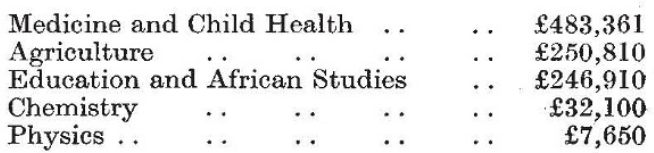

The share of the physical sciences in these funds is meagre. One explanation may be that since these benefactions come from highly industrialized and developed countries, none of the organizations is interested in encouraging basic physical science research in developing countries. Except during the International Geophysical Year and the International Year of the Quiet Sun, when some equipment and limited funds were provided for collecting data from outstations in Africa, all the burden of research in the physical sciences has had to be borne by the resources of the particular developing country. Given the need to provide social amenities, very little money will in fact be available from the governments for any form of research. The very few industries in these countries are usually operated by foreign companies which have their headquarters in the developed countries. Most of their research ean usually be done better in their home countries and therefore they will have little interest in encouraging research in the universities of the country in which they are operating.

\section{The Quality of Radiation}

A REPORT is about to be published by the International Atomic Energy Authority, Vienna, of an international panel meeting held in Vienna last year to discuss the biophysical effects of ionizing radiations of various kinds and properties (Technical Report Series No. 58, Biophysical Aspects of Radiation Quality, I.A.E.A., Vienna, 1966). The subject is important not merely because of its practical value in assessing the hazards due to radiation which is not simple in character, but also because of its interest in fundamental radiobiological research. One of the conclusions of the panel at Vienna was that there is a need of more systematic measurement of energy dissipation in biological material by ionizing radiation of various kinds. The intention is that the activity of the group shall be continued within the framework of a research programme co-ordinated by the international agency, and it is expected that the programme will be more clearly defined at a meeting to be held under the auspices of the agency in 1967 .

Much of the discussion of the technical panel was concerned with the survival curves for cells of various kinds, and with the interpretation of the available experimental evidence. On one model, the results were interpreted in terms of the amount of energy required to produce critical molecular damage in small regions of the nucleus from a mammalian cell possibly not greater than $50 \AA$ in diameter. In the same vein, a model of genetic damage supposing that critical effects are produced by one ionization in each of the very small structures situated more than $100 \AA$ apart, showed that more heavily ionizing atomic particles have a greater probability of doing damage. Other interpretations of cell survival curves described at the meeting of the panel consisted of a model in which the damage done by alpha-particle radiation can be accounted for by the dissipation of between 350 and $500 \mathrm{eV}$ in a small volume of a mammalian cell. (From this discussion it also emerged that the proportion of single-hit killing by X-rays in kidney cells is between 10 and 20 per cent.) Other interpretations of the effects of ionizing radiation on single cells were based on various stochastic models.

\section{Replant Problem}

THE "replant problem" is only one of many which face fruit growers, but solving it could lead to a spectacular increase of yield on many farms. It turns up when fruit trees are planted in ground previously planted with trees of the same species-for example, when apple trees are planted in old apple orchards. The cause is not yet clear, but the result can be a considerable retardation of growth in the first year of the life of a tree and proportional losses throughout. Clearly 